\title{
Certain Building Materials with Respect to Their Thermal Properties as Well as to Their Impact to Environment
}

\author{
Anna Antonyová ${ }^{1}$, Peter Antony ${ }^{2}$, Abdul Halid Abdullah ${ }^{3 *}$, Sasitharan \\ Nagapan $^{3}$ \\ ${ }^{1}$ Faculty of Management, University of Prešov in Prešov, Konštantínova 16, Prešov 08001, Slovak Republic \\ ${ }^{2}$ APmikro,Pavlovičovo námestie 19, Prešov 08001, Slovak Republic \\ ${ }^{3}$ Faculty of Civil and Environmental Engineering, Universiti Tun Hussein Onn Malaysia, Parit Raja 86400, Malaysia
}

Received 8 September 2017; accepted 2 October 2018, available online 24 October 2018

\begin{abstract}
Thermal properties of certain building materials were studied with respect to environmental aspects. The building materials with significant insulation properties were laboratory tested using the special equipment based on Peltier module. During the experimental work, the samples of the following materials were tested: Expanded polystyrene (EPS), Autoclaved aerated concrete (AAC): Ytong, Calcium Silicate Board: Super-Isol and Foam glass (Cellular Glass Insulation): PERINSUL. The temperature was measured directly in connection of material with the Peltier module as well as in the distances of $5 \mathrm{~mm}, 27.5 \mathrm{~mm}, 50 \mathrm{~mm}$ and $95 \mathrm{~mm}$ from the Peltier module. The temperature taken at the surface of Peltier module reached $-22^{\circ} \mathrm{C}$, a typical temperature in the cold winter season. The results of the laboratory experimental work were modelled using the graphic representation. Modelling the thermal distribution will help to determine the ideal material thickness in the design of the building insulation.
\end{abstract}

Keywords: Analysis; building materials; environment; optimization; thermal properties

\section{Introduction}

A few criteria are important when we make decision for the proper insulation material that is used as the building envelopes. Safety, hydrothermal properties and price is considered the most important criteria. Akos Lakatos [1] describes calculations on how the moisture influences the thermal properties of the building materials. At present, the increasing emphasis is put on the environmental aspect [2]. Poor material or material damaged during installation immediately becomes part of the construction and demolition waste. In subsequent modifications and repairs in the building still more materials become integral parts of the waste. Therefore the possibility of further subsequent processing of the material is still more and more important.

This way Zero Waste Technologies are of increasing importance [3]. Reprocessing of demolition waste for the manufacturing of new products is the main topic in the research communities of Olga Finoženok [4] and her Lithuanian colleagues. Indian researchers [5] discuss conditions for the most economic and energy efficient design for construction of residential buildings. Bjørn [6] deals with traditional building insulation materials such as: expanded polystyrene (EPS), extruded polystyrene (XPS), polyurethane, cork, mineral wool and cellulose. The properties as well as possibilities of traditional materials he compares with the requirements, which are put on the modern future materials. Abdou and Budaiwi [7] propose comparison of the building insulation materials according to the values of thermal conductivity using standard ASTM C518 and ISO 8301 protocols. The thermal conductivity, in relation from the historic structures as a cultural heritage to new materials, became an interesting topic also for the research of Maria Stefanidou and her colleagues [8].

In this scientific work the thermal distribution properties to express the heat flow through insulating materials was modeled [9][10][11].

\section{Material and Methodology}

All the experimental testing was managed during the winter time when the weather conditions were appropriate. The Peltier module in this scientific work was used to set the temperature of $-22^{\circ} \mathrm{C}$ to create conditions to measure the temperature in the laboratory, independently of the weather or season. The samples of the various building materials were tested in four points to simulate the conditions, which are typical during the winter time in the central Europe.

To test the thermal properties, we decided for the following building materials:

i. Expanded polystyrene (EPS)

EPS, as a rigid cellular plastic, has a wide range of use. However the contribution focuses on its use as a building 
insulation material. EPS is mostly used to construct a building envelope. EPS is specific with its low weight as well as the low thermal conductivity that ranges 0.035 $0.05 \mathrm{~W} /(\mathrm{m} . \mathrm{K})$.

\section{ii. Autoclaved aerated concrete (AAC), Ytong}

Ytong is a lightweight foam concrete material with a low thermal conductivity and high fire and mould resistanceFig.1 Measured sample of Expanded polystyrene (EPS).Ytong is usually preferred as material for construction of walls as main parts of buildings.

\section{iii. Calcium Silicate Board, Super-Isol}

Super-Isol designed as lightweight insulating boards for maximum temperatures of $1100^{\circ} \mathrm{C}$. This makes it suitable for use primarily in the construction of fireplaces.

iv. Foam glass (Cellular Glass Insulation), PERINSUL PERINSUL is a new, modern building insulation material. It can be used especially to eliminate structural thermal bridging.

\subsection{Method for testing the materials}

The selected building materials were laboratory tested for thermal distribution. At first the tested samples of materials were formed into the blocks with dimensions of 50x40x100mm. Each block was sequentially connected to the Peltier module. Figure 1 shows the block of Expanded polystyrene (EPS) with the temperature sensors. Four temperature sensors number 18B20 Dallas 0352B7, which are placed in the holes in the distances of: $5 \mathrm{~mm}$, $27.5 \mathrm{~mm}, 50 \mathrm{~mm}$ and $95 \mathrm{~mm}$ from the upper part of Peltier module that was used as the abutting element for the cold transfer. The distances were chosen according to our previous experimental work with respect to the detected non-linearity of the process. The holes in the block with the sensors are filled with Vaseline for better heat transfer. The measured samples of material were connected to thermoelectric cooling through Peltier module with conductive silicone sealant.

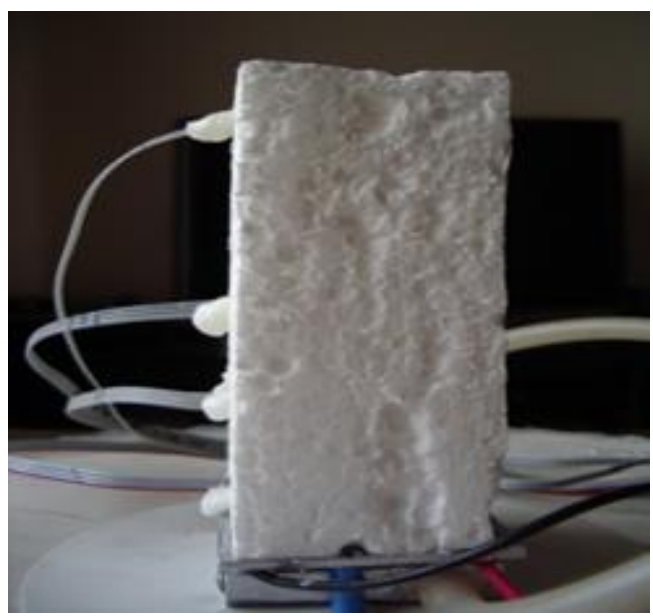

Fig. 1 Measured Sample of Expanded polystyrene (EPS).
Fig. 2 shows measuring equipment based on the Peltier module with the sample of Autoclaved aerated concrete (AAC), Ytong. The water circulates through the equipment. The results of measurements are processed by a processor and displayed on the screen.

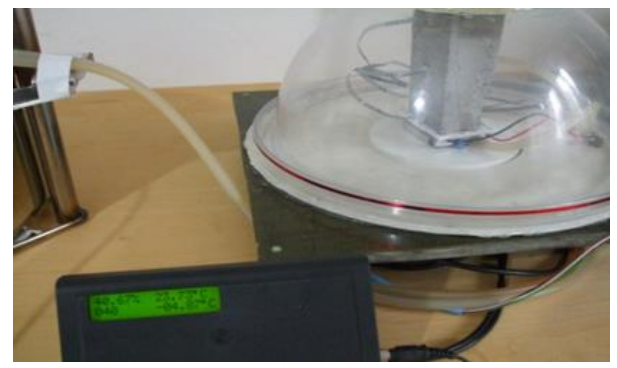

Fig.2 Measuring equipment based on the Peltier module with the sample of Autoclaved aerated concrete (AAC), Ytong.

The temperature is measured on the surface of the Peltier module as well as in the holes placed in the samples of material every 5 minutes. The results with the values in degrees of Celsius are expressed in Figures 3, 4, 5 and 6. $\mathrm{X}$-axis expresses time intervals, when measurements were carried. Y-axis expresses temperature measured with sensors that are placed between Peltier module and sample as well as in the holes, which are in the blocks of the material

\subsection{Results and Discussion}

Figure 3 expresses graphic characteristics of the thermal distribution through the samples of materials.

Fig. 3 (a) expresses graphic characteristic of the thermal distribution throughout the sample of Autoclaved aerated concrete (AAC), Ytong. Ytong is said to be an environmentally friendly material as also already used material may be crushed into small pieces and reuse adding into material while forming a new blocks.

Fig. 3 (b) expresses graphic characteristic of the thermal distribution throughout the sample of Foam glass (Cellular Glass Insulation), PERINSUL. Since glass is the main component in PERINSUL, the recycling process is similar to the glass material recycling.

Fig. 3 (c) expresses graphic characteristic of the thermal distribution throughout the sample of Expanded polystyrene (EPS). EPS is mostly used for building envelopes not only for its suitable hydrothermal properties but also for the reasonable price. Although EPS is not a natural material, from the view point of its further impact on environment, EPS is fully recyclable.

Fig. 3 (d) expresses graphic characteristic of the thermal distribution throughout the sample of Calcium Silicate Board, Super-Isol. Leftover Super-Isol is re-used into new materials. Super-Isol is also re-used to make a new 
material that is suitable for construction a horse-racing track.

(a)

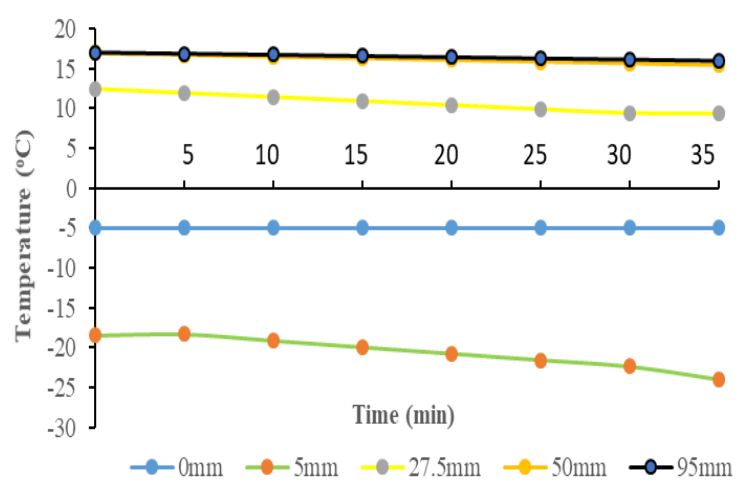

(c)

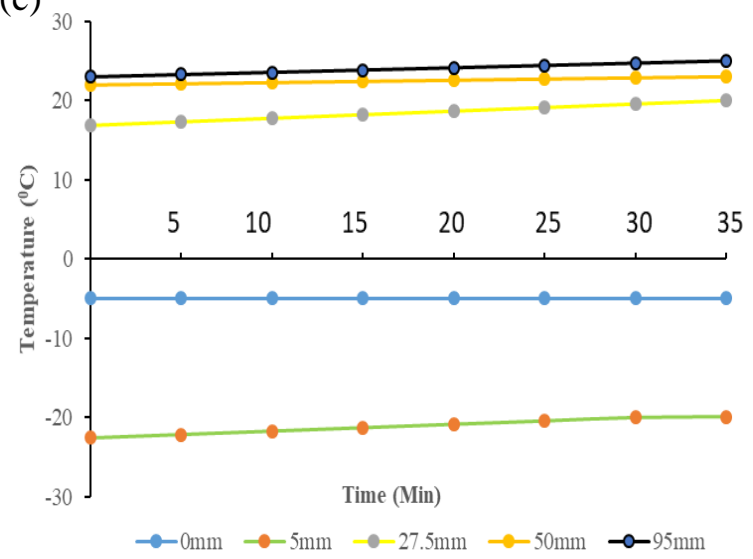

(b)

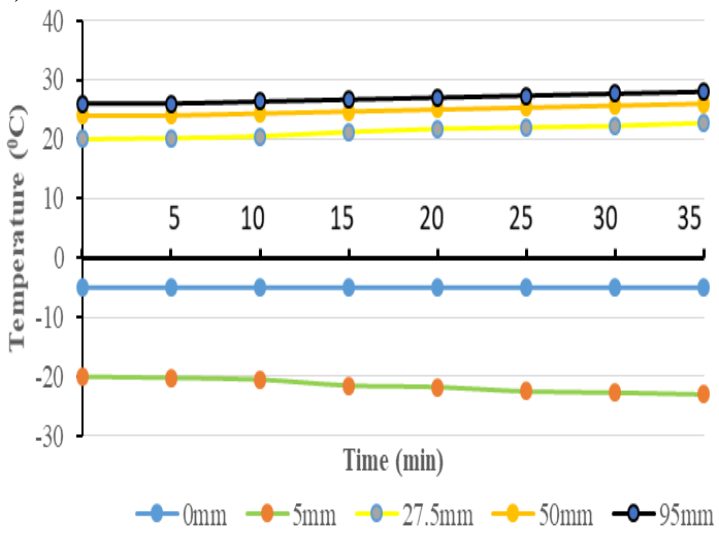

(d)

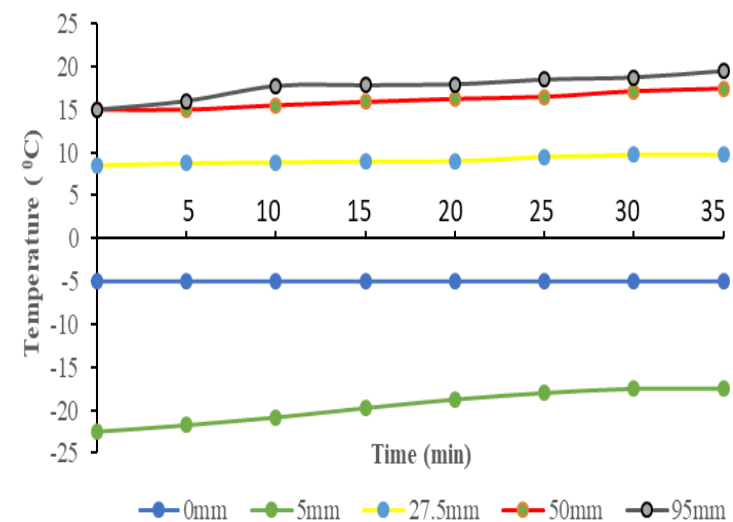

Fig. 3 Graphic characteristics of the thermal distribution throughout the samples of materials: (a) Autoclaved aerated concrete (AAC), Ytong, (b) Foam glass (Cellular Glass Insulation), PERINSUL, (c) Expanded polystyrene (EPS), (d) Calcium Silicate Board: Super-Isol.

The graphic characteristics express the thermal distribution throughout the selected materials as their thermal properties. Since there is only a slight distance between the lines describing the temperature in the distance of $50 \mathrm{~mm}$ and $95 \mathrm{~mm}$, it means that it does not make a great difference if we make decision for material in thickness of $95 \mathrm{~mm}$ or greater.

To set the proper thickness of insulation material the least square as statistical method was used to determine the trend line for thermal distribution throughout the individual materials. Figure 4 expresses graphic characteristic of the thermal distribution throughout the sample of Autoclaved aerated concrete (AAC), Ytong with the trend line for polynomial dependency that is expressed as formula (1).

$y=-0.175 x^{3}-1.6343 x^{2}+24.731 x-45.216$

with the value for index of determination: $R^{2}=0.9943$

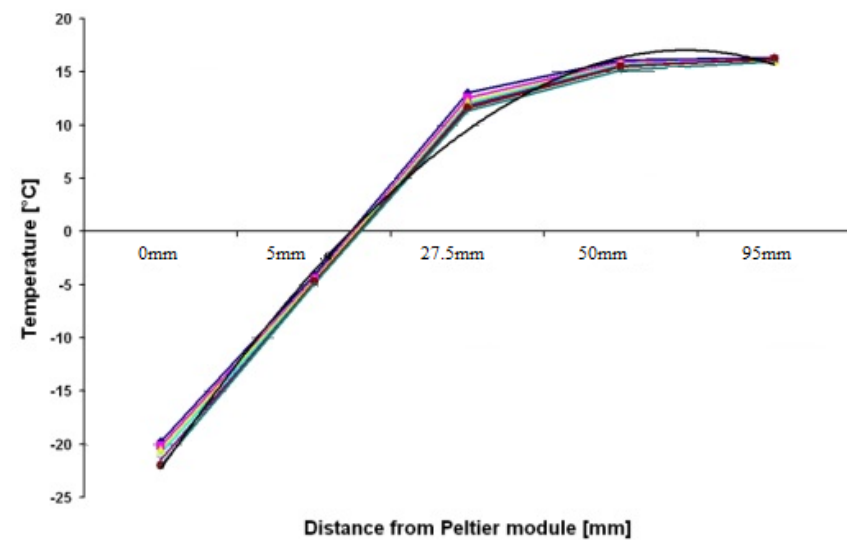

$\rightarrow 0 \mathrm{~min} \rightarrow-5 \mathrm{~min}-10 \mathrm{~min}-15 \mathrm{~min} \rightarrow 20 \mathrm{~min} \rightarrow 25 \mathrm{~min}+30 \mathrm{~min} \longrightarrow$ Polynomický $(30 \mathrm{~min})$

Fig. 4 Graphic characteristic of the thermal distribution throughout the sample of Autoclaved aerated concrete (AAC), Ytong with the trend line for polynomial dependency.

Fig. 5 expresses graphic characteristic of the thermal distribution throughout the sample of Foam glass (Cellular Glass Insulation), PERINSUL with the trend 
line for polynomial dependency that is expressed as formula (2).

$y=-0.2967 x^{3}-0.9821 x^{2}+26.635 x-47.74$

with the value for index of determination: $R^{2}=0.9934$

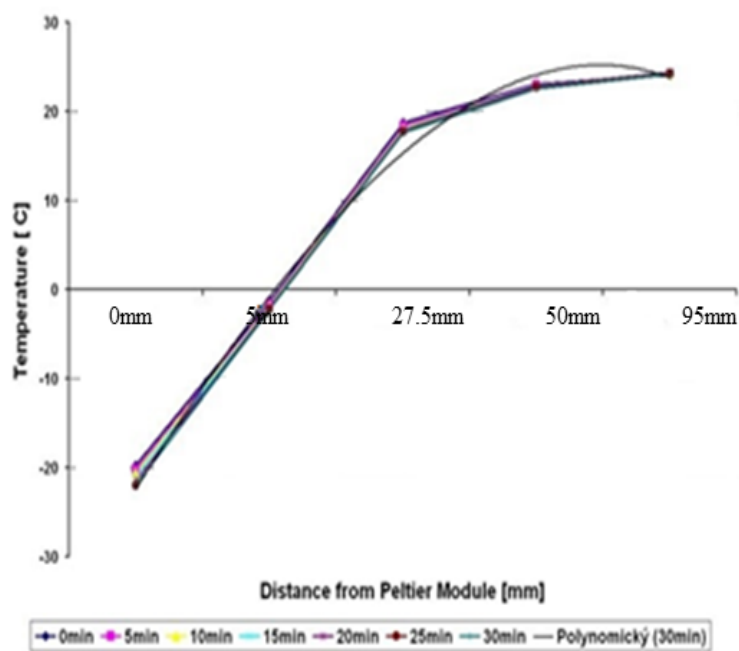

Fig. 5 Graphic characteristic of the thermal distribution throughout the sample of Foam glass (Cellular Glass Insulation), PERINSUL with the trend line for polynomial dependency.

Fig. 6 expresses graphic characteristic of the thermal distribution throughout the sample of Expanded polystyrene (EPS) with the trend line for polynomial dependency that is expressed as formula (3).

$y=0.1 x^{3}-4.6293 x^{2}+35.611 x-51.59$

with the value for index of determination:

$R^{2}=0.9945$

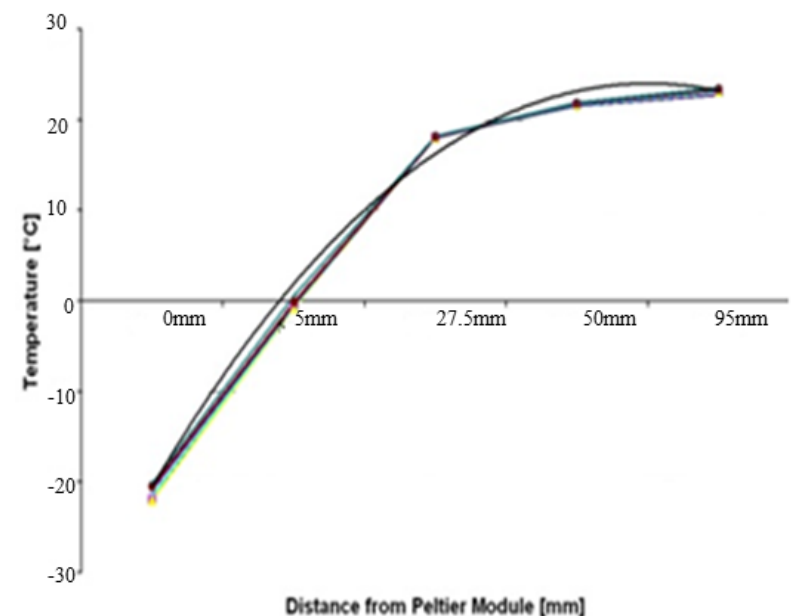

Distance from Peltier Module [mm]

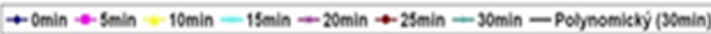

Fig.6 Graphic characteristic of the thermal distribution throughout the sample of Expanded polystyrene (EPS) with the trend line for polynomial dependency.
Figure 7 expresses graphic characteristic of the thermal distribution throughout the sample of Calcium Silicate Board: Super-Isol with the trend line for polynomial dependency that is expressed as formula (4).

$y=-0.27 x^{3}-0.0693 x^{2}+18.471 x-38.486$

with the value for index of determination:

$R^{2}=0.998$

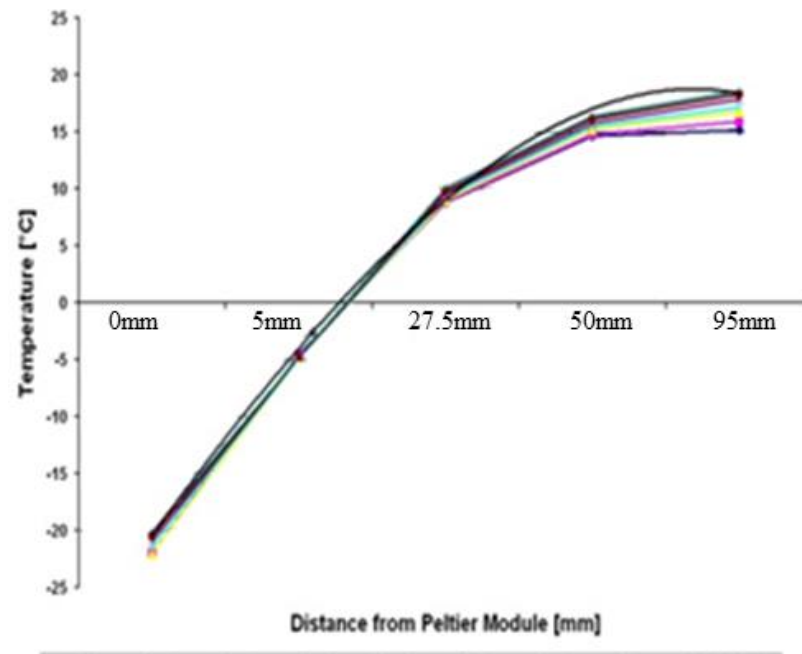

Fig. 7 Graphic characteristic of the thermal distribution throughout the sample of Calcium Silicate Board: SuperIsol with the trend line for polynomial dependency.

In all cases the values for index of determination show satisfactory accuracy.

\subsection{Conclusion}

The presented scientific research focused on testing the thermal properties of building materials. The new technology used Peltier module to set the temperature that is typical for winter time in central Europe. This method allows measuring the thermal distribution throughout materials used for building insulation without the dependency on the season. The contribution proposes testing the following materials: Expanded polystyrene (EPS), Autoclaved aerated concrete (AAC): Ytong, Calcium Silicate Board: Super-Isol and Foam glass (Cellular Glass Insulation): PERINSUL. The samples of materials were placed on Peltier module with the temperature to $-22^{\circ} \mathrm{C}$. The temperature was measured in the samples of materials at points located $5 \mathrm{~mm}, 27.5 \mathrm{~mm}$, $50 \mathrm{~mm}$ and $95 \mathrm{~mm}$ from the surface of the Peltier module with the temperature sensors number 18B20 Dallas $0352 \mathrm{~B} 7$.

The graphic characteristics express the thermal distribution throughout the samples of materials. Analyzing the graphs we can set also the proper thickness 
of the building material that is used for insulation. Analyzing the environmental aspects we decided that chosen materials are environmentally friendly and are suitable for recycling as well as for reuse.

\subsection{Acknowledgements}

This research was supported by the University of Prešov in Prešov international research grant no.43636-14/16 entitled "Modeling of environmental management processes".

\section{References}

[1] Lakatos, Á., Moisture induced changes in the building physics parameters of insulation materials. Science and Technology for the Built Environment, Volume 22(3), (2016), pp. 252-260.

[2] Abdulrahman, A., Latiff, A.A.A., Daud. Z., Ridzuan, M.B. \& Jagaba, A.H., Preparation and Characterization of Activated Cow Bone Powder for the Adsorption of Cadmium from Palm Oil Mill Effluent. IOP Conference Series: Materials Science and Engineering. Volume 136(1), (2016), 012045.

[3] Daud, Z., Awang, H., Kassim, A.S.M., Hatta, M.Z.M. \& Aripin, A.M., Comparison of pineapple leaf and cassava peel by chemical properties and morphology characterization. Advanced Materials Research. Volume 974, (2014), pp. 384-388.

[4] Finoženok, O., Žurauskienè, R., \& Žurauskas, R., Reprocessing of Buildings' Demolition Waste and Utilization for the Manufacturing of New Products. Journal of Civil Engineering and Architekture, Volume 6(9), (2012), pp. 1230-1239.

[5] Jagruthi, K., Ciddarth, N., \& Kannan, M.R., Life cycle assessment of thermal insulating building materials using building information modelling. ARPN Journal of Engineering and Applied Sciences, Volume 9(3), (2014), pp. 223-232.

[6] Jelle, B.P., Traditional, state-of-the-art and future thermal building insulation materials and solutions Properties requirements and possibilities. Energy and Buildings, Volume 43(10), (2011), pp. 25492563.

[7] Abdou, A.A., \& Budaiwi, I.M., Comparison of Thermal Conductivity Measurements of Building Insulation Materials under Various Operating Temperatures. Journal of Building Physics, Volume 29 (171), (2005), pp.171-184.

[8] Stefanidou, M., Assael, M., Antoniadis, K., \& Matziaroglou, G., Thermal Conductivity of Building Materials Employed in the Preservation of Traditional Structures. International Journal of thermophysics, Volume 31(4), (2010), pp. 844-851.

[9] Abdullah, A.H., Bakar, S.K.A., \& Rahman, I.A., Indoor Thermal Performance of an Office Building using Conventional Brick Versus Interlocking Compressed Earth Brick (ICEB) Wall. International
Journal of Construction Technology and Management, Volume 1 (1), (2013), pp. 22-27.

[10] Nagapan, S., Rahman, I.A., Asmi, A., \& Adnan, N.F., Study of Site's Construction Waste in Batu Pahat, Johor. Procedia Engineering, Volume 53, (2013), pp. 99-103.

[11] Antonyova, A., Korjenic, A., Antony, P., Korjenic, S., Pavlusova, E., Pavlus, M., \& Bednar, T., Hygrothermal properties of building envelopes: Reliability of the effectiveness of energy saving. Energy and Buildings, Volume 57, (2013), pp.187192. 